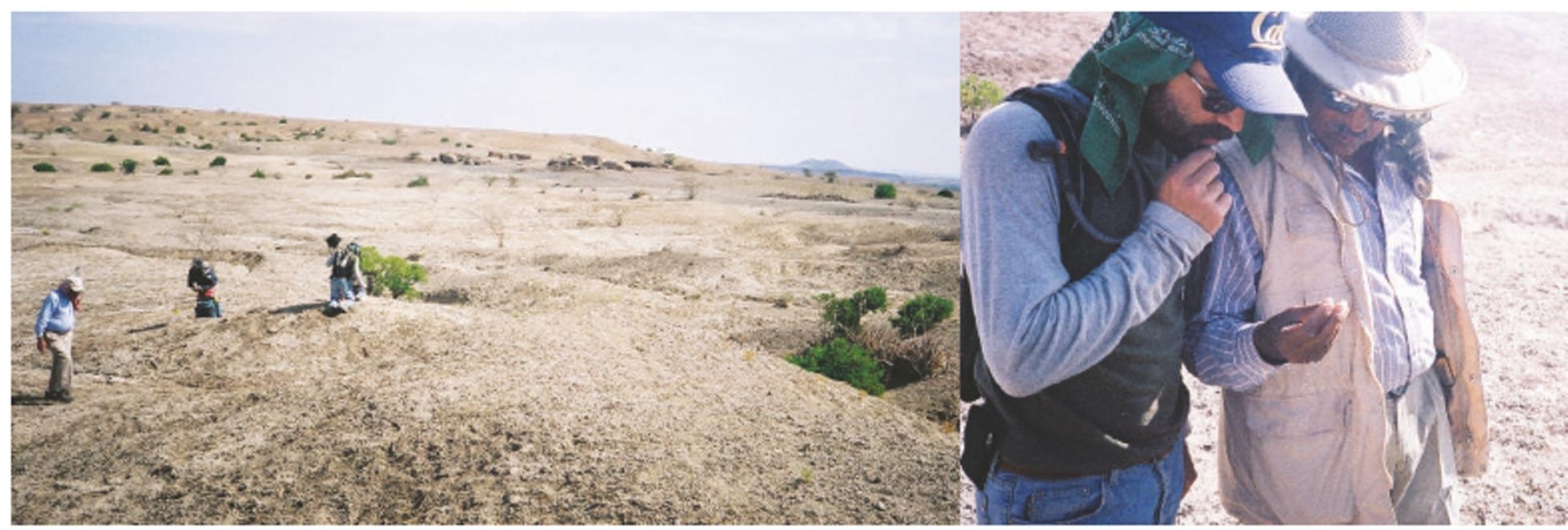

\section{Feel it in your bones}

\section{Deciding whether our ancestors evolved as a single lineage may depend more on philosophy than fossils. Rex Dalton reports.}

The human family tree may now be a lot cleaner, according to the discoverers of a cache of fossils on a hillside in Ethiopia.

The researchers say the fossils, from the Afar region, go a long way towards showing that early hominids were not a diverse group of coexisting species. The team suggests three species evolved as a single lineage between at least 4.4 million years ago and 2.9 million years ago - an era when humankind refined its ability to walk upright while developing new ways to live (see timeline).

The idea is one of the most contentious in palaeoanthropology. The fossil trove, reported earlier this month (T. D. White et al. Nature $440,883-889$; 2006) has confirmed some important aspects of the trail towards the genus Homo, which appeared around $2.3 \mathrm{mil}-$ lion years ago. But experts are still bickering over the relationship between the species that have been found.

The latest report describes 30 fossils, belonging to at least eight individuals of Australopithecus anamensis; before the discovery, the only known specimens of this species came from northern Kenya, about 1,000 kilometres to the southwest (M. G. Leakey et al. Nature 376, 565-571; 1995). The Afar specimens date to 4.1 million years ago, and were dug from ravines cut by rain at a site called Asa Issie, meaning red hill. They are the latest discovery made by the Middle Awash project, an international team that has explored these geological formations for nearly 25 winters.

An hour's walk to the northeast of Asa Issie is the Aramis site, where the team found fossils of an earlier species called Ardipithecus ramidus, dated to 4.4 million years ago. An hour's walk to the east lie fossils of Australopithecus afarensis - the species to which Lucy belongs, dated to 3.4 million years ago. Many consider $A$. afarensis to be the immediate predecessor of the genus Homo. It was first identified at Hadar, about 70 kilometres north of Asa Issie, and lived until at least 2.9 million years ago in eastern Africa.

\section{Theory of relativity}

An understanding of our own species' lineage is crucial to building a picture of how early hominids evolved, their gait, diet and tools, and the effects of the environment. Experts have squabbled over the relationship between Ar. ramidus, Au. anamensis and Au. afarensis ever since they were discovered: some believe each species evolved directly into the next, and others insist that they lie on separate branches of the family tree.

The latest Afar discovery is exciting experts because it shows that the three hominids existing in the same area, but in successive time periods. Tim White of the University of California, Berkeley, co-leader of the Awash team, believes this points to a direct lineage between the three - a process called phyletic evolution.

The new Au. anamensis fossils are only 300,000 years younger than Ar. ramidus, meaning that if one became the other, the changes would have had to happen that fast. But the key point, says White, is that fossils of Au. anamensis and Au. afarensis have never been found in sediments the same age as those containing Ar. ramidus. If fossils of the different species were found together, that could show that they belonged to multiple lineages existing simultaneously.

Finding remains of all three species in the same area but not from the same time period suggests they did not coexist, says White. The team confirmed the dates using several geological dating methods on layers of rock above and below the fossils, along with examinations of other animal fossils found, including antelopes, monkeys and pigs.

The specimens also provide anatomical clues to evolutionary history. ${ }^{\alpha}$ The new Au. anamensis fossils are anatomically intermediate between the earlier Ar. ramidus and the later Au. afarensis," says White. For example, the teeth of the newly discovered Au. anamensis fossils seem adapted to chew tougher and more abrasive foods than Ar. ramidus. The researchers believe this shows that Au. anamensis had a broader diet.

${ }^{\alpha}$ All this strengthens the view that there is phyletic evolution from Ar ramidus through Au. anamensis," says White. He believes he has nailed down the relationship between the two later species, although he says that further specimens are needed to prove the earlier link.

This month's Nature paper makes a bold argument, and shows the Awash team seeking to put its mark on the record. Others in the field are impressed. ${ }^{\alpha}$ When you find 30 new hominid fossils, you are allowed a certain amount of conjecture," says Bernard Wood, a palaeoanthropologist at George Washington University in Washington DC. "As always, they have done a fantastic job. 


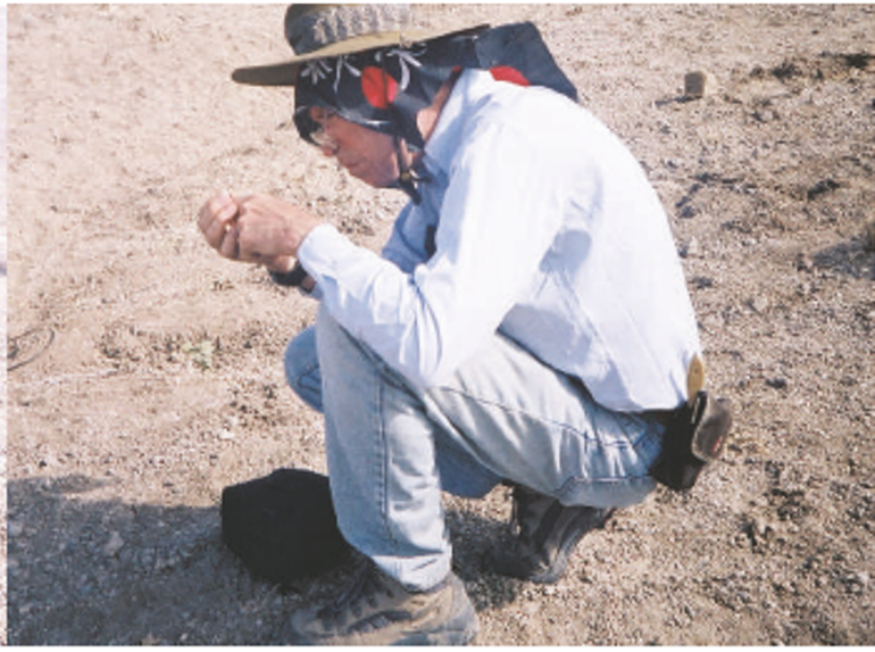

Rock on: members of the Middle Awash project have been hunting hominid fossils in Ethiopia for $\mathbf{2 5}$ years.

But he and others are unconvinced by the Awash team's conclusion: ${ }^{\alpha}$ This is only the first half of the rugby match," says Wood.

Meave Leakey, lead author on the Au. anamensis discoveries in Kenya, is more blunt. "I don't believe this," she says. "We do not have the specimens to fill the gaps."

\section{Ancestral pile-up}

Leakey and Wood are among those who believe that other, as yet undiscovered hominid species may have lived at this time, from 4.4 million to 2.9 million years ago. The existence of other species would cloud or eliminate the argument for a direct lineage. ${ }^{\alpha} \mathrm{My}$ prejudice is there are more lineages rather than fewer - more diversity," says Wood. "I have to concede these new data are dramatic. But we should beware coming out with a complete explanation when we don't have all the evidence."

This argument frustrates White. "There were Martians there back then too, he says. "And spacecraft all over the Pliocene - we just haven't found them yet."

Similar arguments run for various phases of hominid evolution, for example whether Homo ergaster evolved into $H$. erectus, or whether they were two coexisting lineages - White advocates the former. But ultimately, the argument comes down to the point that more fossils could always be found, so it is unclear that the two sides will ever agree.

In the meantime, the new Au. anamensis fossils are at the Ethiopian National Museum in Addis Adaba, where they will augment the Middle Awash hominid collection, which spans nearly 6 million years. ${ }^{\alpha}$ The discovery at Asa Issie is really wonderful," says Mamitu Yilma, the museum's director. ${ }^{\alpha}$ This strengthens the museum as an ideal centre to study human evolution."

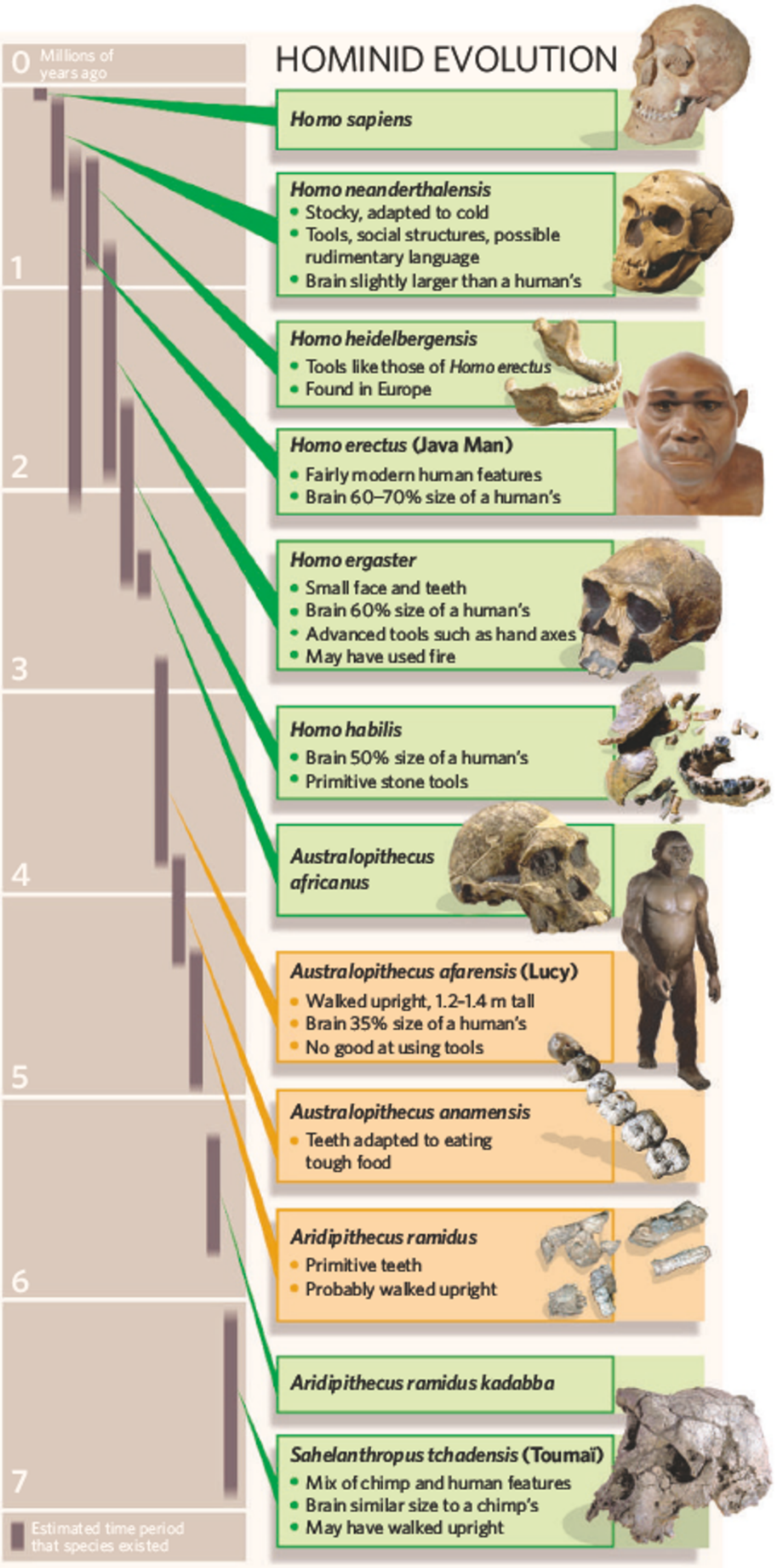

